\title{
Effect of Reactive Diluents on the AC Electrical Treeing in Epoxy/Nanosilicate Systems
}

\author{
Jae-Jun Park ${ }^{\dagger}$ \\ Department of Electrical and Electronic Engineering, Joongbu University, Geumsan 312-702, Korea
}

Received January 22, 2014; Revised January 27, 2014 Accepted February 3, 2014

\begin{abstract}
The effect of reactive diluents on the ac electrical treeing in epoxy/nanosilicate systems was studied, in a needle-plate electrode geometry. Diglycidyl ether of bisphenol A (DGEBA) type epoxy was used as a base resin, and layered silicate was used as a nano-sized filler. Polyglycol (PG) or 1,4-butanediol diglycidyl ether (BDGE) was introduced as a reactive diluent to the DGEBA/nanosilicate system, in order to decrease the viscosity of the nanocomposite system. PG acted as a flexibilizer, and BDGE acted as a chain extender, after the curing reaction. To measure the treeing propagation rate, a constant alternating current (ac) of $10 \mathrm{kV} / 4.2 \mathrm{~mm}(60 \mathrm{~Hz})$ was applied to the specimen, in a needle-plate electrode arrangement, at $30^{\circ} \mathrm{C}$ of insulating oil bath. When $10 \mathrm{kV} / 4.2 \mathrm{~mm}(60 \mathrm{~Hz})$ was applied, the treeing propagate rate in the DGEBA system was $1.10 \times 10^{-3} \mathrm{~mm} / \mathrm{min}$, and that in the DGEBA $/$ PG system was $1.05 \times 10^{-3} \mathrm{~mm} / \mathrm{min}$. As 1.5 $w t \%$ of nanosilicate was added to the DGEGA/PG system, the propagation rate was $0.33 \times 10^{-3} \mathrm{~mm} / \mathrm{min}$. This meant that the nano-sized layered silicates would act as good barriers to treeing propagation. The effect of chlorine content was also studied, and it was found that chlorine had a bad effect on the electrical insulation property of the epoxy system.
\end{abstract}

Keywords: Electrical treeing, Epoxy nanocomposite, Reactive diluent, Propagation rate

\section{INTRODUCTION}

Epoxy resins have good mechanical and thermal properties, as well as excellent electrical properties, thus they have been used as insulation materials in the field of heavy electric equipment, such as mold-type transformers, current transformers (CT), potential transformers (PT), metering out-fit (MOF), gas switching gears, and so on [1-3]. In order to achieve these performances, many kinds of inorganic fillers, such as silica $\left(\mathrm{SiO}_{2}\right)[4]$, alumina $\left(\mathrm{Al}_{2} \mathrm{O}_{3}\right)$ [5], mica [6], aluminum nitride (AlN) [7], and titanium dioxide $\left(\mathrm{TiO}_{2}\right)[8]$, have been incorporated into the epoxy resins.

However, when inorganic filler was incorporated into an epoxy resin, the viscosity became too high. So it was very difficult not only to disperse the fillers homogeneously and to remove bubbles from the epoxy/filler mixture, but also to inject the viscous mixture into a mold, during the curing process. Therefore,

${ }^{\dagger}$ Author to whom all correspondence should be addressed: E-mail: jjpark@joongbu.ac.kr

Copyright $@ 2014$ KIEEME. All rights reserved. This is an open-access article distributed under the terms of the Creative Commons Attribution Non-Commercial
License (http://creativecommmons.org/licenses/by-nc/3.0) which permits unrestricted noncommercial use,
distribution, and reproduction in any medium, provided the original work is properly cited.

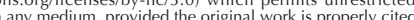

in order to decrease the viscosity, plasticizers, organic solvents or reactive diluents were introduced to the epoxy/filler composites, so that bubbles were easily removed from the composites, after injection into a mold.

However, the plasticizers disturbed the cure reaction of the epoxy system, so that the crosslink density decreased. This caused decrease of the electrical, mechanical and thermal properties of the epoxy system. Also, when organic solvent was used, it should be removed completely, after mixing epoxy, fillers and organic solvent. If not, it might act as an impurity, so that the electrical, mechanical and thermal properties of the epoxy composite would be negatively affected. Reactive diluents were used, in order to decrease the viscosity during mixing, and the electrical treeing phenomena was studied, in order to estimate the insulative characteristics of neat epoxies or their nanocomposites, because the treeing phenomena has often been referred to as the most important mechanism for the deterioration of polymeric insulators (e.g. high voltage polymeric cables) [9-12]. The treeing growth mechanism was divided into three processes: (1) incubation process, (2) initiation process, and (3) propagation process. If an electrical treeing was initiated, it would propagate rapidly, and breakdown would finally occur. Hence, the initiation time should be delayed, and the propagation rate be retarded, in or- 
der to get excellent insulation polymeric materials.

In this study, two epoxy/reactive diluent/nanosilicate systems for the insulative materials of heavy electric equipments were prepared, and the effect of reactive diluent on the electrical treeing phenomena was studied, in needle-plate electrodes.

\section{EXPERIMENTS}

\subsection{Materials}

A commercial DGEBA (diglycidyl ether of bisphenol A) type epoxy resin was used, of trade name YD 128 (Kukdo Chem. Co.). The equivalent weight was $184 \sim 190$, and the viscosity was $11,500 \sim 13,500 \mathrm{cps}$ at $25^{\circ} \mathrm{C}$. The curing agent was Me-THPA (3or 4-methyl-1,2,3,6-tetrahydrophthalic anhydride), whose grade name was $\mathrm{HN}-2200$ (Hitachi Chem. Co.). It is widely used in the field of electric insulation. An accelerator was BDMA (benzyldimethyl amine, Kukdo Chem. Co.). A reactive diluent employed as a flexibilizer was a polyglycol (PG), under the trade name DY040 (Ciba-Geigy Co.). Its molecular weight was about 7,000 10,000, and its viscosity was $60 \sim 90 \mathrm{cps}$ at $25^{\circ} \mathrm{C}$. Another reactive diluent as an aliphatic epoxy resin was purchased from Kukdo Chem. Co., under the trade name of BDGE. Its equivalent weight was 120 140, and its viscosity was $15 \sim 30 \mathrm{cps}$ at $25^{\circ} \mathrm{C}$. Its chlorine content was 25,000 ppm (max). Low-chlorine epoxy resin, whose chlorine content was 4,000 ppm ( $\max$ ), was supplied by Hajin Chemtech Co. Cloisite ${ }^{\circledR} 10$ A (Southern Clay Products, Inc.), and was used as a layered silicate, which was organically modified with 2MBHT (dimethyl-benzyl-hydrogenated tallow quaternary ammonium), as a sort of quaternary ammonium salt. It was also dried at $110^{\circ} \mathrm{C}$ for $24 \mathrm{~h}$ in vacuum oven, and stored in desiccator, before use. A needle-type steel electrode was purchased from Ogura Jewelry Co., Japan. Its diameter and length were $1 \mathrm{~mm}$ and $60 \mathrm{~mm}$, respectively, with a tip angle of $30^{\circ}$, and a curvature radius of $5 \mu \mathrm{m}$.

\subsection{Specimen preparation for ac treeing test}

To prepare the epoxy/reactive diluent/nanosilicate systems, DGEBA (100 g)/reactive diluent (10 g) and Cloisite $10 \mathrm{~A}(2.74 \mathrm{~g})$ were mixed with ultrasonic homogenizer $(20 \mathrm{kHz})$ for $30 \mathrm{~min}$, and then put into an ac electric field apparatus developed by us [13]. The ac electric field was generated by a high voltage (HV) generator, in the following conditions; (1) inter-electrode distance: $50 \mathrm{~mm}$, (2) application voltage: $11 \mathrm{kV}$, (3) frequency: $1 \mathrm{kHz}$, and (4) application time: $60 \mathrm{~min}$. During the ac application time, epoxy resin penetrated into the interlayer, making the layered silicate swollen. Then, the mixture was mixed with THPA (80 g) and BDMA $(0.9 \mathrm{~g})$. The weight percent of nanosilicate in the epoxy nanocomposite was $1.5 \mathrm{wt} \%$.

The mixture was poured into a mold having a cavity of $15 \times 15$ $\mathrm{mm}^{2}$ with $30 \mathrm{~mm}$ height, in which a needle electrode was arranged beforehand, to make the distance of needle-plate electrodes be $4.2 \mathrm{~mm}$. Then, it was cured at $120^{\circ} \mathrm{C}$ for $2 \mathrm{hr}$, and postcured at $150^{\circ} \mathrm{C}$ for $2 \mathrm{hr}$, and then cooled slowly at a rate of $-0.5{ }^{\circ} \mathrm{C}$ /min until room temperature, to avoid internal stress. Finally, the opposite side of the needle electrode in the epoxy specimen was coated with conductive silver paste.

\subsection{AC treeing test}

To measure the treeing rate at a constant alternating current (AC) of $10 \mathrm{kV} / 4.2 \mathrm{~mm}(60 \mathrm{~Hz})$, the specimen with needle-plate electrode arrangement was inserted into the insulating oil at $30^{\circ} \mathrm{C}$, and maintained sufficiently for $2 \mathrm{hr}$, until the temperature of the needle tip area reached oil temperature. Then, high volt- age (HV) was applied, by using AC Endurance Voltage Tester (Haefely, Germany), at a rising speed of $1 \mathrm{kV} / \mathrm{s}$ until $10 \mathrm{kV}$; and the test voltage was kept, until electrical breakdown took place. The treeing morphology was monitored by a video microscope system (ICS-305B, SOMETECH Inc.), with the treeing images being collected every $1 \mathrm{~min}$.

\section{RESULTS AND DISCUSSION}

Figure 1 shows the treeing growth rate in three epoxy systems, under the constant AC electric field of $10 \mathrm{kV} / 4.2 \mathrm{~mm}(60 \mathrm{~Hz})$, at $30^{\circ} \mathrm{C}$. The three epoxy systems were neat DGEBA system, DGEBA system with PG as a reactive diluent, and DGEBA/PG system with nanosilicate. In the DGEBA system, the propagation rate of the electrical treeing was $1.10 \times 10^{-3} \mathrm{~mm} / \mathrm{min}$, and breakdown finally took place in $3,794 \mathrm{~min}$. In the DGEBA/PG system, the treeing propagation rate was $1.05 \times 10^{-3} \mathrm{~mm} / \mathrm{min}$, which was 1.05 times slower, and the breakdown time was $3,996 \mathrm{~min}$, which was 1.05 times lower than that of the DGEBA system. These results meant that there was almost no effect of PG on the tree propagation rate. As $1.5 \mathrm{wt} \%$ of nanosilicate was added to the DGEGA/PG system, the propagation rate was $0.33 \times 10^{-3} \mathrm{~mm} / \mathrm{min}$, which was 3.2 times slower than that of the DGEBA/PG system. This meant that the nano-sized layered silicates were well dispersed in the epoxy matrix, and that they would act as good barriers to treeing propagation [14].

The morphology of electrical treeing for the DGEBA/PG system is shown in Figure 2. The typical behavior of branch type electrical treeing was obtained from the morphology observation. That is to say, when a constant AC electric field of $10 \mathrm{kV} / 4.2$ $\mathrm{mm}(60 \mathrm{~Hz})$ was applied, electrons were injected and extracted at the needle tip, so that small electrical treeing was faintly initiated from the needle tip (Fig. 2 (a)). Then, electrons injected and extracted at the newly generated conductive treeing tip- which had been carbonized, so that several branches were newly appeared, and they grew rapidly, became fatter and darker, with many new branches (Figs. 2 (b) and 2 (c)), and finally, the penetration breakdown took place, from the needle tip to silver electrode plate (Fig. 2 (d)).

Electrical treeing phenomena for DGEBA and DGEBA/PG/ nanosilicate systems were compared to those of the DGEBA/ PG system, as shown in Fig. 3. Fewer branches were shown in the DGEBA system than those of the DGEBA/PG system, as displayed in Fig. 3(b). In a similar time of the propagation state, the primary branches formed with few new secondary branches. That is to say, electrons that were injected and extracted at the needle tip generated small electrical treeing from the needle tip in the initial stage, and then electrons were injected and extracted at the newly generated primary treeing tip, which had been carbonized. Because there were no barriers in the DGEBA system, the treeing grew straight from the needle electrode to the plate electrode. However, the treeing shape was bush type, and the length grew very slowly, as shown in Figs. 3 (e) and 3 (f). The treeing became fatter and darker, without any new branches. These results meant that the treeing growth was disturbed by the dispersed silicate monolayers. The bush type tree might be because the momentum power of the injected electrons couldn't pass through the silicate monolayers, so they should develop a new root, to avoid the silicate monolayers. It was a time-consuming process. Therefore, it was found that well-dispersed silicate monolayers acted as good barriers to the treeing propagation.

Figure 4 shows treeing growth rates for the DGEBA, DGEBA/ PG and DGEBA/BDGE systems, and those for the three nanosilicate nanocomposites are also compared in the same figure. In the DGEBA/PG/nanosilicate system, it was found that the tree- 


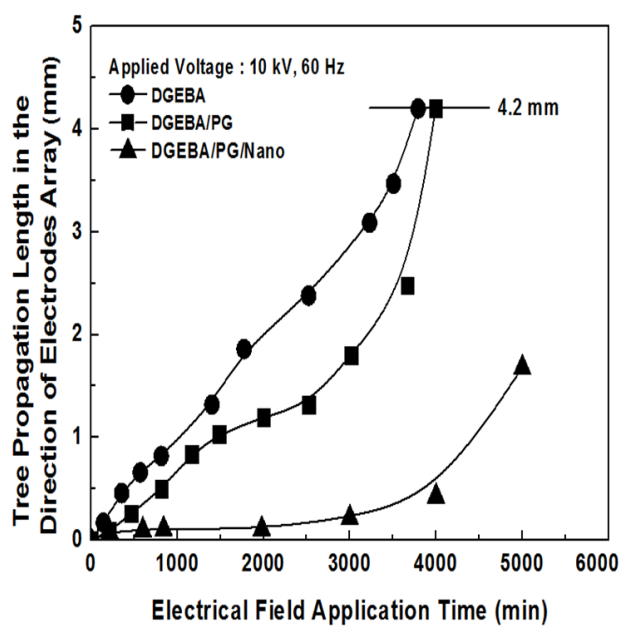

Fig. 1. Effect of PG and nanosilicate on the treeing growth rate, in the various epoxy systems tested, in the constant electric field of 10 $\mathrm{kV} / 4.2 \mathrm{~mm}(60 \mathrm{~Hz})$, at $30^{\circ} \mathrm{C}$.

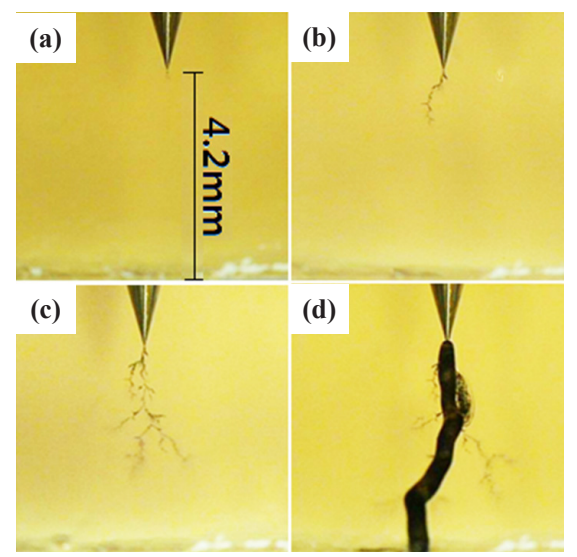

Fig. 2. Electrical treeing morphology of the DGEBA/PG system, tested in the constant electric field of $10 \mathrm{kV} / 4.2 \mathrm{~mm}(60 \mathrm{~Hz})$, at $30^{\circ} \mathrm{C}$, for (a) $300 \mathrm{~min}$, (b) 1,650 min, (c) 3,650 min, and (d) 3,996 min.

ing growth was disturbed by the dispersed silicate monolayers, as was previously explained. The barrier effect of the nanosilicate layers in the other two systems was also found. In the DGEBA system, the propagation rate of the electrical treeing was $1.10 \times 10^{-3}$ $\mathrm{mm} / \mathrm{min}$, while that in the DGEBA/ nanosilicate system was $1.07 \times 10^{-3} \mathrm{~mm} / \mathrm{min}$, which was 1.03 times slower. In the DGEBA/ BDGE system, the propagation rate of the electrical treeing was $1.15 \times 10^{-3} \mathrm{~mm} / \mathrm{min}$, while that in the DGEBA/BDGE/nanosilicate system was $1.13 \times 10^{-3} \mathrm{~mm} / \mathrm{min}$, which was 1.02 times slower. The barrier effect of the nanosilicate layers in DGEBA and DGEBA/ BDGE systems was very low, compared to 3.2 times in the DGE$\mathrm{BA} / \mathrm{PG}$ system. These results indicated that a synergetic effect of PG and nanosilicate layers was found.

The treeing morphologies for each epoxy system and its nanosilicate system are compared in Fig. 5. A shorter treeing propagation was displayed in the DGEBA/PG system, and far shorter treeing propagation was shown in the DGEBA/PG/nanosilicate system, this meant that PG could slightly retard the treeing propagation rate, and a synergetic effect of the PG and nanosilicate layers was found. Therefore, PG could be used as a reactive diluent in the DGEBA system, withoutdeterioration of the insulation breakdown property. However, BDGE could not be used as a reactive diluent, because it gave some degradation effect to the

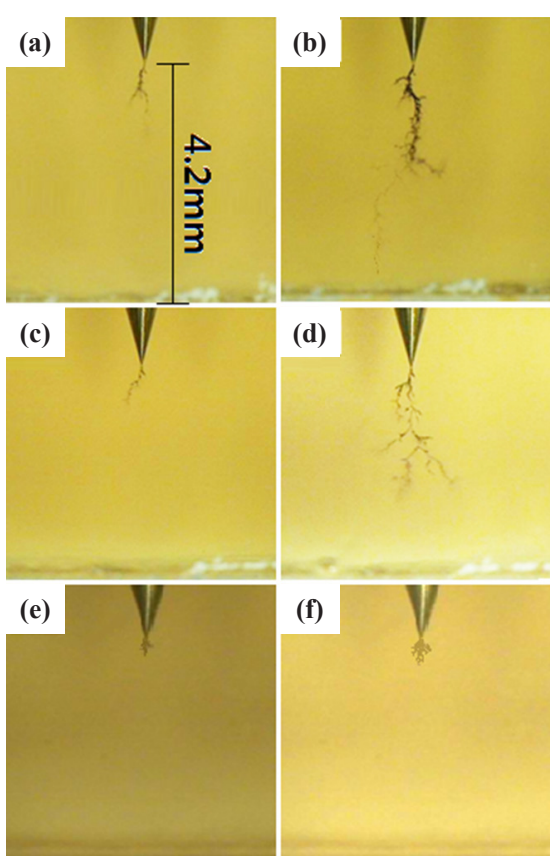

Fig. 3. Electrical treeing morphology of the various epoxy systems, tested in the constant electric field of $10 \mathrm{kV} / 4.2 \mathrm{~mm}(60 \mathrm{~Hz})$, at $30^{\circ} \mathrm{C}$ : (a) $420 \mathrm{~min}$, (b) 3,550 min in the DGEBA system; (c) 1,050 min, (d) 3,650 min in the DGEBA/PG system, (e) 2,520 min, and (f) 4,050 min in the DGEBA/PG/nanosilicate system.

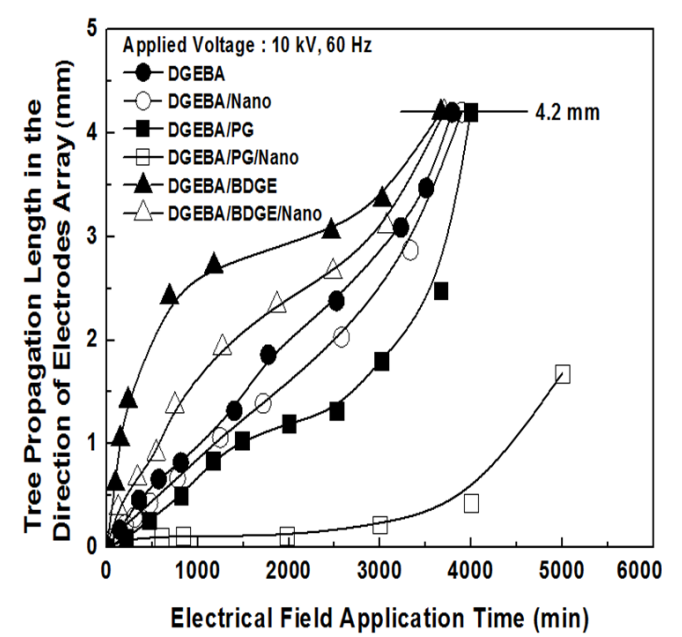

Fig. 4. Effect of reactive diluents and nanosilicate on the treeing growth rate, in the various epoxy systems with and without layered silicate, tested in the constant electric field of $10 \mathrm{kV} / 4.2 \mathrm{~mm}(60 \mathrm{~Hz})$, at $30^{\circ} \mathrm{C}$.

insulation breakdown property.

Figure 6 shows the effect of chlorine content in the DGEBA/BDGE/ nanosilicate system on the treeing growth rate, tested in the constant electric field of $10 \mathrm{kV} / 4.2 \mathrm{~mm}(60 \mathrm{~Hz})$, at $30^{\circ} \mathrm{C}$, and the electrical treeing morphologies are shown in Fig. 7. The treeing growth rate for DGEBA/BDGE systems with low-level chlorine was 1.10 times slower than that of the system with high-level chlorine. The branch type treeing morphology showed a bad effect of the chlorine element. This may have been due to the easy reaction between the epoxide group and chlorine atom, so that a loose crosslink network was formed [14]. 

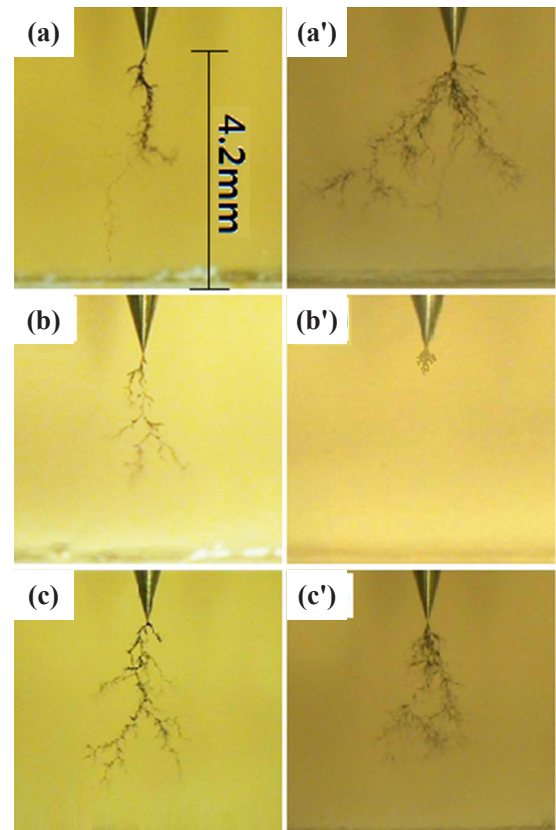

Fig. 5. Electrical treeing morphology of various epoxy systems, with and without nanosilicate, tested in the constant electric field of 10 $\mathrm{kV} / 4.2 \mathrm{~mm}(60 \mathrm{~Hz})$, at $30^{\circ} \mathrm{C}$ : (a) 3,550 min (DGEBA), (a') 3,550 mm (DGEBA/nanosilicate), (b) 3,650 min (DBEBA/PG), (b') 4,050 min (DBEBA/PG/nanosilicate), (c) 3,550 mm (DGEBA/BDGE), and (c') 3,550 min (DGEBA/BDGE/nanosilicate).

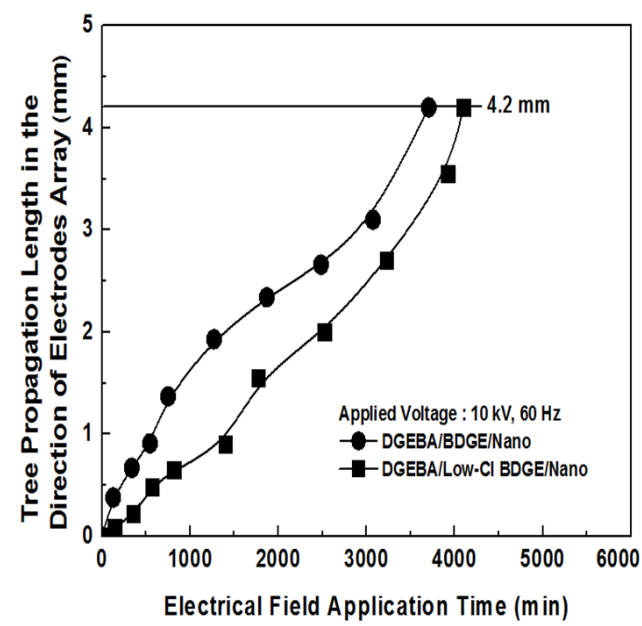

Fig. 6. Effect of chlorine content in the DGEBA/BDGE/nanosilicate system on the treeing growth rate, tested in the constant electric field, of $10 \mathrm{kV} / 4.2 \mathrm{~mm}(60 \mathrm{~Hz})$, at $30^{\circ} \mathrm{C}$.

\section{CONCLUSIONS}

The effects of reactive diluents on the AC electrical treeing in epoxy/nanosilicate systems were studied, by carrying out a treeing test, at constant alternating currents (AC) of $10 \mathrm{kV} / 4.2$ $\mathrm{mm}(60 \mathrm{~Hz})$, in needle-plate electrode geometry. In the DGEBA system, the propagation rate was $1.10 \times 10^{-3} \mathrm{~mm} / \mathrm{min}$, and that in the DGEBA/PG system was $1.05 \times 10^{-3} \mathrm{~mm} / \mathrm{min}$. As $1.5 \mathrm{wt} \%$ of nanosilicate was added to the DGEGA/PG system, the propagation rate was $0.33 \times 10^{-3} \mathrm{~mm} / \mathrm{min}$. This meant that the nano-sized layered silicates would act as good barriers to treeing propaga-

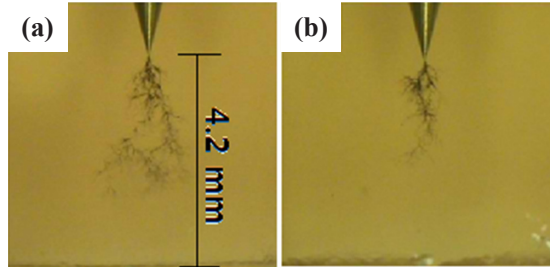

Fig. 7. Electrical treeing morphology of the (a) DGEBA/BDGE, and (b) DGEBA/BDGE (low-Cl), tested in $15 \mathrm{kV} / 4.2 \mathrm{~mm}(60 \mathrm{~Hz})$, at $30^{\circ} \mathrm{C}$, for 3,550 min.

tion, and a synergetic effect of PG and nano-sized layered silicate was found. The effect of chlorine content was also studied, and it was found that chlorine had bad effect on the electrical insulation property of the epoxy system.

\section{ACKNOWLEDGMENT}

This work was supported by Joongbu University (2013).

\section{REFERENCES}

[1] J. Y. Lee, M. J. Shim and S. W. Kim, Polym. Eng. Sci., 39, 1993 (1999) [DOI: http://dx.doi.org/10.1002/pen.11592].

[2] Y. S. Cho, M. J. Shim and S. W. Kim, Mater. Chem. Phys., 66, 70 (2000) [DOI: http://dx.doi.org/10.1016/S0254-0584(00)002728].

[3] R. Sarathi, R. K. Sahu and P. Rajeshkumar, Mater. Sci. Eng.: A, 445, 567 (2007) [DOI: http://dx.doi.org/10.1016/ j.msea.2006.09.077].

[4] P. O. Henk, T. W. Kortsen and T. Kvarts, High Perform. Polym., 11, 281 (1999) [DOI: http://dx.doi.org/10.1088/09540083/11/3/304].

[5] M. Ehsani, Z. Farhadinejad, S. Moemen-bellah, S. M. Bagher alavi, M. M. S. Shrazi and H. Borsi, $26^{\text {th }}$ Internal Power System Conference, Tehran, Iran, 11-E-CAM-2359 (2011).

[6] P. Bajaj, N. K. Jha and A. Kumar, J. Appl. Polym. Sci., 56, 1339 (1995) [DOI: http://dx.doi.org/10.1002/app.1995.070561015].

[7] Y. Xu, D. D. L. Chung and C. Mroz, Composites: Part A, 32, 1749 (2001) [DOI: http://dx.doi.org/10.1016/S1359835X(01)00023-9].

[8] A. A. Wazzan, H. A. Al-Turaif and A. F. Abdelkader, PolymerPlastics Technology and Engineering, 45, 1155 (2006) [DOI: http://dx.doi.org/10.1080/03602550600887285].

[9] T. Tanaka, G. C. Montanari and R. Mülhaupt, IEEE Trans. Dielectr. Electr. Insul., 11, 763 (2004) [DOI: http://dx.doi. org/10.1109/ TDEI.2004.1349782].

[10] T. Imai, F. Sawa, T. Ozaki, T. Shimizu, R. Kido, M. Kozako and T. Tanaka, Intern. Sympos. Electr. Insulating Materials, Kitakyushu, Japan, pp. 239 (2005).

[11] J. J. Park and J. Y. Lee, IEEE Trans. Dielectr. Electr. Insul. 17, 1516 (2010) [DOI: http://dx.doi.org/10.1109/TDEI.2010.5595553]

[12] D. J. Suh and O. O. Park, J. Appl. Polym. Sci., 83, 2143 (2002) [DOI: http://dx.doi.org/10.1002/app.10166].

[13] J. J. Park and J. Y. Lee, IEEE Trans. Dielectr. Electr. Insul. 17, 1516 (2010) [DOI: http://dx.doi.org/10.1109/TDEI.2010.5595553].

[14] J. J. Park, Trans. Electr. Electron. Mater., 14, 278 (2013) [DOI: http://dx.doi.org/10.4313/TEEM.2013.14.5.278].

[15] L. P. Witnauer, H. B. Knight, W. E. Palm, R. E. Koos, W. C. Ault, and D. Swern, Ind. Eng. Chem., 47, 2304 (1955) [DOI: http:// dx.doi.org/10.1021/ie50551a034]. 